\title{
Os signos do afeto: subjetividade e formas de vida na obra Lavoura arcaica, de Raduan Nassar
}

\author{
Alex Fabiano Correia Jardim*
}

\begin{abstract}
Resumo
Problematizaremos os signos de afeto no romance Lavoura arcaica e suas implicações na produção de uma "des-natureza" e de paradoxos. As passagens se darão do discurso litúrgico-moral até uma heterogeneidade que recusa o antigo pertencimento. No romance, razão, paixão e fé são representadas a todo instante nos diálogos da trama, servindo como justificativa dos discursos, sejam eles expressos pelo pai ou pelo filho. Raduan Nassar nos apresenta elementos da culpa, da lei, do castigo, do trágico, da morte e da alegria, todos eles, sob a forma de um fluxo narrativo descontínuo e visceral, onde as relações humanas são estabelecidas não só pelo dever, mas também por uma violência física e psíquica, onde o corpo "grita" muito mais alto que a racionalidade. O problema que cruzará o nosso texto será: que pode a criação literária enquanto obra de arte (criação estética) nos ensinar sobre as relações humanas? Escrever não estaria vinculado a uma "rachadura" do eu em lugar de sua recomposição? Que significa pensar ou dizer o mundo através da criação literária enquanto uma estética ou arte da escrita? Nesse caso, a literatura de Raduan Nassar constrói uma estética, seja pelo estilo da escrita, seja pelo ser de sensações que ela cria.

Palavras-chave: Afeto. Transgressão. Identidade.
\end{abstract}

Ao pretendermos tratar dos signos de afeto no romance Lavoura arcaica, de Raduan Nassar, nos deparamos com dois temas importantes, a ideia de uma "des-natureza" e a presença de alguns paradoxos. Nesse sentido, Raduan Nassar não pretende simplesmente povoar a consciência de objetos ou dar a ela um estatuto de organizadora do mundo. A partir dos acontecimentos na trama, parece-nos emergir em sua literatura uma intenção de "traçar um plano no caos" sob a forma de uma "outra" sensibilidade. Nessa direção, vamos propor uma leitura da obra fazendo alguns breves recortes filosóficos, em especial, com o pensamento de Gilles Deleuze, que em alguns momentos aparecerá de

* Universidade Estadual de Montes Claros - UNIMONTES-MG. 
maneira bem visível, outras vezes, um pouco invisível no texto. No capítulo 3 da obra Diferença e repetição (1988), Gilles Deleuze aponta-nos como é constituída uma imagem dogmática do pensamento e nesse itinerário, ele também apresenta que, diferente de uma tradição, o pensamento só é possível a partir de uma violência.

No romance de Raduan Nassar, o personagem André é o polo dessa passagem que vai de uma imagem dogmática (exercício concordante das faculdades) ao livre pensamento, este, impulsionado por uma violência que marca o corpo e o espírito. Na tríade razão, paixão e tradição, razão e tradição se compõem enquanto fundamento da família, instituição por excelência, de forte apelo religioso e/ou teológico. Por outro lado, a paixão se apresenta enquanto elemento trágico e transgressor de uma ordem estabelecida e de uma moral constituída por uma cultura fortemente religiosa. Numa clara alusão à parábola do filho pródigo, Raduan Nassar apresenta-nos um movimento que vai da partida de um filho, com os sentimentos deixados para trás, a ruptura com a família, o retorno, o reencontro com a mãe, o confronto com o pai, até as causas e efeitos de um pensamento delirante envolvido pelo desejo e pelo amor à irmã, indicativos de um incesto, este, a degenerescência máxima do espírito da razão e da moral. No texto, razão, paixão e fé são representadas a todo instante nos diálogos da trama, misturando-se constantemente e servindo como justificativa dos discursos, sejam eles expressos pelo pai ou pelo filho. A noção de família, de liberdade, do tempo, do amor, do trabalho, da verdade, são todas tratadas sob diferentes perspectivas filosóficoteológicas, sejam elas coletivas (centralizadas no patriarcalismo familiar) ou individuais (expressas no desejo e no delírio do jovem André, o filho). Quando falamos de "signos" que torcem e retorcem uma subjetividade, o romance de Raduan Nassar tem elementos da culpa, da redenção, da lei, do castigo, do trágico, da morte e da alegria. Por fim, nos deparamos com o desdobramento dessa tensão, onde a culpa, proveniente do incesto cometido pela jovem Ana cede lugar à alegria, à satisfação, ao contentamento, sentimentos expressos numa dança frenética e alucinada em meio às comemorações pelo retorno do irmão pródigo. Por outro lado, a temperança também se esvai diante de tal cena. O patriarca, reto e firme na moral, num rompante de loucura e insensatez, toma-se de passividade e vira um agente da morte. É a partir dessa ambiguidade de sensações que Raduan Nassar constrói a narrativa.

Em Lavoura arcaica, repetimos, as relações humanas são estabelecidas não unicamente pelo dever e pelo respeito, mas também, por uma violência 
física e psíquica. Tal perspectiva corrobora perfeitamente com a afirmação deleuzeana de que há no mundo alguma coisa que força a pensar, e essa força ou encontro fundamental, neste caso, os signos de amor entre André e Ana, instalam a potência de uma singularidade, de uma vida. Nesse movimento, poderíamos dizer que a literatura de Raduan Nassar constrói uma estética, seja pelo estilo da escrita, seja pelo ser de sensações que ela cria ou inventa. No texto Lavoura arcaica, Raduan Nassar apresenta o pensamento não como um mero uso concordante das faculdades, mas como o efeito de uma violência. O romance já se inicia com a descrição da cena de um encontro entre dois irmãos, André e Pedro. André, atormentado por um amor transgressor, destoa de uma vida moral constituída pela tradição, pelo respeito aos preceitos religiosos, familiares e por uma racionalidade que conduz a modos de vida disciplinar e reto. Ele, André, é um torto. Pedro, pelo contrario, é a figura da correção, do respeito, a voz e espelho de um Pai que conduz a vida de todos em função de procedimentos indicados por uma crença, por um dogma: o respeito ao passado da família e a palavra de Deus. Pedro é a figura da representação. Carrega em seus ombros os pressupostos que constituem uma existência ou um regime de vida. Pedro, enquanto "olhos do pai", utiliza o discurso da verdade e, com ela, acredita perfeitamente "no que significa pensar". Pedro é experiência viva de uma afinação entre a imagem e a verdade. E corrobora com essa imagem da verdade a imagem moral. É desta maneira que a conversa entre André e Pedro se desenvolve. Num misto de fluxo da palavra e do silêncio, discurso e contemplação, há uma inconteste luta pelo estabelecimento da verdade. No caso de Pedro, a verdade é preestabelecida pela produção de culpa em André. E no caso de André, a verdade deve ser demolida em favor de uma crítica dura e mordaz acerca dos costumes e da autoridade. Mas em ambos, a conversação é marcada por uma violência. O diálogo, tal como uma corredeira, vai deixando cair pelo caminho ressentimentos, desejos, medos e tradição. É assim, de maneira direta e desde já dando o tom do romance que Nassar faz com que alguma coisa aconteça: a escrita como obra de arte, um bloco de sensações, conjunto de afetos. Raduan faz do seu texto um campo de perceptos, ou seja, consegue fazer vazar o "insensível do sensível”, irredutível ao seu criador ou a quem o experimenta.

Pedro, maciço de pedra talhada pelo pai, insiste na ideia do bem e do amor, pressupostos para uma boa natureza do pensamento. E se André, árvore torta, anomalia da vida, o contrapõe, é porque o paradoxo, imagem deformante do pensamento pretende abdicar de todas as formas de representação. Estamos 
diante de um jogo em que André apresenta as razões de sua perdição, guardando ainda em silêncio o motivo maior: o incesto com Ana. E nesse jogo, a memória exerce um papel importante, pois ela será o fio do tempo que ainda não se quebrou. No discurso de André, afecção e afecto tornam a fala por vezes incompreensível para Pedro. André vive a sua experiência-limite, enquanto Pedro, protegido pela carapaça da moral e da verdade, não compreende o labirinto por onde André agora caminha, se perde e se reencontra. Esse labirinto é formado pelo seu corpo, seus líquidos, sua lembrança, seu amor, seu pensamento desmedido e desfigurado. É essa a agonística que percorre André e a função do pensamento é livrá-lo de todo o caos que porventura poderia lhe destruir, dado que o caos nos atiça uma profunda vontade de morte.

Raduan Nassar utiliza-se de elementos que dão contornos ao romance: representação, memória, desejo, redenção, transgressão, paixão, vida e morte. Todos eles compõem a vida de André. A partir do Terceiro Capitulo torna-se mais intensa a relação entre a representação e a memória, afinal, a primeira forja no espírito e este, por extensão, no corpo, a marca indelével do código, como uma lente da alma, já que os "olhos são a candeia do corpo". (NASSAR, 2005, p. 13). E o que era o corpo de André? O que ele podia? Quais as afecções que o afligiam e o tornava tenebroso, confuso, perdido? $\mathrm{O}$ recolhimento numa pensão, venezianas fechadas, quarto escuro. E é André quem diz: “...eu estava escuro por dentro, não conseguia sair da carne dos meus sentimentos". (NASSAR, 2005, p. 13). Mas Pedro não entendia, dado que estava preso às formas do senso comum. Para ele, o único interesse era resgatar, trazer de volta ao seio da família, da docilidade, do apaziguamento, aquele que se apresentava selvagem e disforme. André: anomalia, torção, reviravolta. Se Pedro não experimenta o exercício do pensamento, André vive sua violência. Condenado ao sentimento de culpa quando a força da lembrança o faz pensar "nos olhos da mãe”. (NASSAR, 2005, p. 15). Embriagado pelo vinho e pelo delírio da experiência-limite do pensamento, André desconsidera as possibilidades de compreensão por parte do irmão daquilo que o inquieta. Diferente de Pedro, André fez da vida um problema. Tornou-a uma complicação. E o pano de fundo, o objeto de um encontro desencadeador desse delírio do pensar é Ana, materialização do amor, do desejo. Ana é o signo que porta as condições de uma fissura, "a violência daquilo que força a pensar". (DELEUZE, 1988, p. 233).

Diante das leis da sobriedade da razão, a construção da narrativa de Nassar também nos confronta com o inevitável da desrazão. O pensamento 
em André é movido não somente pelo amor transgressor, mas também pela cólera em relação aos costumes, aos hábitos que edificam uma moral. Falamos de descontentamento que produz agressão. Como afirmou Perrone-Moisés, "a cólera é a paixão dos impacientes, curioso paradoxo se nos lembrarmos que a palavra paixão e a palavra paciência têm a mesma etimologia: passio, isto é, sofrimento". (PERRONE-MOISÉS, 2001, p. 61). E a impaciência é a força motriz que leva André à vertigem do corte, da separação, afinal, "a impaciência também tem os seus direitos!" (NASSAR, 2005, p. 88). A família, santuário puro da verdade, da união e do trabalho, onde cada um deveria, imperativamente, fazer a sua parte, resguardar seu papel, cumprir a sua lei. Um tipo de cuidado de si e dos outros, sem desvio, sem desejos particulares. Era esse inclusive o reiterado discurso do Pai, catedral da verdade. É diante desse quadro que André se impacienta. Se, por um lado, temos a parcimônia da razão (Pai), do outro, teremos a densidade da impaciência e da cólera (Filho). É nesse confronto que o romance se desdobra. Entre a partida e o retorno, não haverá mais harmonia e nem a esperança de um recomeço. Algo se quebrou. Uma parábola do filho pródigo ao reverso. O passado, se contraído num jogo de culpa promovido pelo discurso do Pai, não afeta André. Pelo contrario, o passado faz de André um desmedido em que a perversão encontra morada. Escapando-se à afinidade, à filiação em relação ao verdadeiro, André não se arrepende da acusação de promover a discórdia. Se ele aceita o discurso do Pai é para aliviar o cansaço dos apelos do corpo: reprimido e torcido por gritar suas vontades. Este corpo conduzido, até então, pelos enunciados sempre negativos da tradição.

Valendo-nos da velha proposição espinosana, perguntamos: o que pode um corpo? Seja ele simbólico ou físico, material. O corpo da família, dos objetos da casa, das regras, do pai, de Ana, da mãe, de Pedro, o corpo de André: corpo a-significado, alógico e sem designação. Corpo dessemelhante. Diferencial. Obscuro. André singular. Espasmo vertiginoso de uma forma de vida que rompia com a sua velha identidade de filho-cordeiro. Se não há identidade, não há um eu. Não há uma forma; teremos o não-reconhecido ou então uma reflexão na loucura. Esse eu fendido ou fissurado de André degrada o ideal de mundo através da sexualidade perversa. Num diálogo com Pedro, André diz de si mesmo, colocando-se naquele momento enquanto terceira pessoa: o que faz dele um diferente? Que crime hediondo ele cometeu? Com essas duas questões/proposições, André salienta seu desvio. Algo se passou de tal forma que outrora o espaço, seus corpos-estrutura que constituem a tradição 
e o tempo, curso regular e cíclico, tornam-se desprovidos de uma docilidade ou contiguidade. E é o amor perverso que a tudo muda. Tudo dissolve. E no romance, este amor é uma des-natureza. André é o puro paradoxo. Linha fronteiriça entre a afirmação da vida e a sua negação. O amor de André não é necessariamente uma graça ou uma dádiva, mas sim um fardo, um peso, uma carga, conforme ele mesmo afirma quando diz "não tenho culpa desta chaga, deste cancro, desta ferida, não tenho culpa deste espinho, não tenho culpa do meu delírio". (NASSAR, 2005, p. 136).

Para André, há sempre algo que o incomoda, ou seja, o aspecto desconhecido do mundo, das coisas, das pessoas. Isto é, haverá sempre os riscos de um mundo indeterminado, longe do alcance daquele pai-lavrador. $\mathrm{Ou}$ seja, o romance estabelece uma relação entre duas ordens em plena diáspora: André/filho, aquele que transforma em corpo a palavra do patriarca, esta última, consciência translúcida e recorrente dos valores que sobrevoam o tempo; e André materialidade de um elemento diferencial que não pertence nem a ele e nem ao pai, mas circula através deles. André experimenta o elemento diferenciante e vive seus excessos sobre si mesmo. Por isso que o amor que ele sente pela irmã, torção de um amor reto e natural, o impele ao desconhecido, sem que isso o faça temer o fracasso.

$\mathrm{O}$ estabelecimento de um plano de organização familiar torna-se urgente para todos que estão nela implicados: pai, mãe, filhos, irmãos e irmãs, reduzindo-a à consciência (patriarcal), como se regras do pai funcionassem como um conjunto ordenado em que a "sua" consciência promovesse uma síntese constitutiva universal. Mas nem sempre o mundo permanece tão bem ordenado. O próprio plano de organização da tradição moral e religiosa lhe escapa e pedaços de caos voltam a perturbar André, tornando-o uma versão obscura e trágica da parábola do filho pródigo. E no seu retorno, André continua a viver um tipo de noite insondável que perpassa os objetos-corpos de sua casa ou do seu antigo mundo. O retorno não vem seguido de redenção e nem reconciliação: André, figura transgressora e consumida pelo desejo, ao mesmo tempo em que re-constituía um mundo à luz da sua razão, vê esse mundo invadido pelo nonsense. Para André, enunciar, marcar, ordenar e administrar indica um exercício de poder: "não reconheço mais os valores que me esmagam”. (NASSAR, 2005, p. 162). "A única coisa que sei é que todo meio é hostil, desde que negue direito à vida". (NASSAR, 2005, p. 165). E todo esforço do Pai é por marcar poder, por dar uma pouco de ordem ao caos. "Já basta de extravagâncias, não prossiga mais neste caminho, não se 
aproveitam teus discernimentos, existe anarquia no teu pensamento, ponha um ponto na tua arrogância, seja simples no uso da palavra". (NASSAR, 2005, p. 166). Cada estocada do pai, arremessa André num devir assubjetivo, num eu deformado e dissolvido, que destoa de uma consciência constituinte que determina uma forma-homem: "Pertenço como nunca desde agora a essa insólita confraria dos enjeitados, dos proibidos, dos recusados pelo afeto, dos sem-sossego, dos intranquilos, dos inquietos." (NASSAR, 2005, p. 138-139).

Seria possível para André, contrariando os sermões do Pai, "jogar-se contra os limites da representação e subvertê-la?” (PRADO JÚNIOR, 2004, p. 170). Mas não em função de um novo homem ou humanidade. A ideia seria escapar do binômio verdadeiro e falso. E é nesse itinerário narrativo que André torna infértil o terreno e a lavoura onde foi semeada a pálida obsessão pela virtude. Se o pai diz: o mundo das paixões é o mundo do desequilíbrio, é contra ele que devemos esticar o arame das nossas cercas, André responde: era Ana, era Ana, Pedro, era Ana a minha fome... Era Ana a minha enfermidade, ela a minha loucura, ela o meu respiro, a minha lâmina, meu arrepio, meu sopro...

Eu tinha de gritar em furor que a minha loucura era mais sábia que a sabedoria do pai, que a minha enfermidade me era mais conforme que a saúde da família, que os meus remédios não foram jamais inscritos em compêndios, mas que existia uma outra medicina (a minha!), e que fora de mim eu não reconhecia qualquer ciência, e que era tudo só uma questão de perspectiva... (NASSAR, 2005, p. 107 e 109).

É no meio, sempre no meio desses discursos entre a autoridade e a subversão que André retorna para casa. Mas os signos que levariam à solução já não passam de uma penumbra latente de um passado que não se reconstitui com o presente. Algo se quebrou. O espírito de André já não reconhece e nem representa os estados de coisas. Os festejos pela volta. A agonia atenuada. A culpa, a mágoa, a redenção, "todo um mundo de micropercepções que nos leva ao imperceptível”. (DELEUZE, 1998, p. 61). André não é mais o mesmo. Dessemelhança. Diferença: "não reconheço mais os valores que me esmagam". (NASSAR, 2005, p. 162). André é a figura do dissenso. Retrato de um marginal abandono às forças intempestivas da paixão. Se a transgressão e as palavras pronunciadas por André soam como blasfêmia, isso indicaria para o pai uma doença, mas, contrariamente, para o próprio André, a impressão é que agora ele finalmente estaria experimentando uma grande saúde: "na minha doença existe uma poderosa semente de saúde". (NASSAR, 2005, p. 160). 
A dessubjetivação ou produção de uma "outra forma de subjetividade" em André ocorre justamente por um conjunto de problemas que o transformam, sem origem ou gênese. É uma heterogeneidade molecular que recusa o antigo pertencimento. Não há mais uma recognição dos valores, mas uma potência sem identidade, explodindo sentido e desejo. Anárquica mistura física, social, biológica, linguística. Ingênua revolução dos amantes, "e de mãos dadas, iremos juntos incendiar o mundo!" (NASSAR, 2005, p. 106). André é a dobra mais radical do desejo. Apesar do silêncio de Ana, que se consome pela culpa e pelo medo, a paixão entre eles permanece. E a vazão a este desejo desencadeará um trágico final ao romance. Ana desaparecia, não para resguardar a lei ou a ordem, mas para remoer no silêncio, o prazer pelo vivido, os instintos mais escondidos. Ana é a imagem sombria e precursora do corte, da vertigem, daquilo que é assustador nas pessoas, ou seja, do desejo que quer satisfação e que explode num último instante, transcorrendo, de forma volúvel e cheia de êxtase, o espaço da festa, onde a família e a comunidade festejavam o retorno do filho insano.

Doce ilusão da razão. Se Ana, elemento diferenciante, manteve-se distante do embate entre André e o Pai, procurando na lembrança do amor vivido uma forma de encontrar uma coragem perdida, agora, feito cavalo alado, ela se compõe muito mais com o demoníaco do mundo. Com esse espírito, Ana responde a André, à paixão a que ambos se entregaram, embaralhando diante dos outros as velhas noções de uma educação disciplinar: "Ana (que todos julgavam sempre na capela) surgiu impaciente numa só lufada, os cabelos soltos espalhando lavas". (NASSAR, 2005, p. 186).

Varando com a peste no corpo, o círculo que dançava, introduzindo com segurança, ali no centro, sua petulante decadência, assombrando os olhares de espanto, suspendendo em cada boca o grito, paralisando os gestos por um instante, mas dominando a todos com seu violento ímpeto de vida. (NASSAR, 2005, p. 186-187).

Neste momento em que Ana se torna um grande acontecimento, ela também se apresenta enquanto intensidade e diferença. Dessa maneira Ana expressa a sua impaciência, qualidade e atributo que compõe com André uma sinuosa dança. Para amar, é preciso dividir fardos, assim como dividir os corpos. Quem ama planta e colhe. Plantar e colher são faces do amor, momentos particulares de um mesmo movimento. E a dança de Ana é o seu grito por liberdade, sem escapatórias. Na sua dança, ela assume, fala, ouve, grita, geme e suspira. É a 
Ana da desmedida. Dos exageros. Sem dose certa. Sem juízo perfeito e nem verdade estabelecida. Sem concordância. Por isso ela incomoda. Transborda e desassossega. $\mathrm{O}$ encontro entre André e Ana, suas singularidades devidamente afetadas, parece correr para a morte. Eles mergulham na vida. Mergulho indizível pela alma e pelo corpo. Sem começo e sem caminho. Sem gênese e sem fim. Por vezes, sem volta. Entre a dança solar de Ana e a agonia telúrica de André, haverá o mergulho de um fôlego só. Inflexível. Humano. Intransigente. Se Ana anteriormente foi indiferente pelo silêncio, agora, com a sua dança, descrita no fim do romance de Raduan Nassar, ela afaga, toca carinhosamente em André: "Eu estava certo, mais certo do que nunca, de que era para mim, e só para mim, que ela dançava". (NASSAR, 2005, p. 189). Em seu balé aéreo, ela diz um basta... frenética busca por uma outra forma de vida. Tanto para Ana, como para André, amor é incompatível com a servidão e todo o teatro familiar é um grande simulacro do ideal de vida. André e Ana, cada um à sua maneira, conseguem se aproximar de uma natureza primitiva e reconciliar-se com as suas próprias forças. A esse movimento denominamos arte de viver ou de existir. Simultaneamente essa apoteótica dança e expressão, que reduzia à tolice o que outrora era conhecido por temperança, equilíbrio e razão. Saltando de uma vida que é sentida a outra que é pensada, carregado de ódio e paixão, o patriarca, voz audível entre o passado e o presente, muralha robusta que dividia a vida entre a verdade e o erro, desfaz-se do manto sagrado da compreensão e do entendimento. Deixa cair, ao solo arcaico de sua lavoura, todas as máscaras que o tempo não foi capaz de destruir. Lembremo-nos novamente da proposição espinosana: ninguém sabe o que pode um corpo.

A testa nobre de meu pai, ele próprio ainda úmido de vinho, brilhou um instante à luz morna do sol enquanto o rosto inteiro se cobriu de um branco súbito e tenebroso, e a partir daí todas as rédeas cederam, desencadeando-se o raio numa velocidade fatal: o alfanje estava ao alcance de sua mão, e, fendendo o grupo com a rajada de sua ira, meu pai atingiu com um só golpe a dançarina oriental (que vermelho mais pressuposto, que silêncio mais cavo, que frieza mais torpe nos meus olhos!) (...) Mas era o próprio patriarca, ferido nos seus preceitos, que fora possuído de cólera divina (pobre pai!), era o guia, era a tábua solene, era a lei que se incendiava. (NASSAR, 2005, p. 191).

A insuportabilidade de uma verdade travestida pelos engodos de uma história, do tempo, dos hábitos. Como fala André, "pobre família a nossa, prisioneira de fantasmas tão consistentes!” (NASSAR, 2005, p. 191). A 
insuportabilidade de uma verdade que desterritorializa mundos. É dessa maneira que o romance de Raduan Nassar finaliza a tessitura das relações. Nada é tão rígido. Nada é tão flexível. A vida se consolida num composto de encontros onde o indeterminável, estrangeiro morador das casas, das famílias vai fazendo a sua melodia. Podemos chamá-lo de desejo. Talvez denominálo de sombria natureza humana que constrói silenciosamente os personagens, virtualmente, aguardando o instante, o dispositivo ou uma série qualquer para o seu aparecimento. No final, André, Ana e o Pai, todos são traidores. Se os dois primeiros traem o mundo das significações e transgridem uma ordem estabelecida, o Pai deixa-se sucumbir pela verve furiosa da paixão, tornandose um outro, perdendo a sua identidade, seu rosto. Nesse jogo movediço, todos desaparecem por entre as leis das determinações objetivas. Nesse novo teatro, não há mais segredo, já não há fantasia.

No fim do romance, nos deparamos com o encontro da diferença com o paradoxo. Não há mais sujeitos. Não há mais estrutura. Um tipo de naufrágio do ego ou o fim da antinomia entre corpo e espírito. Fracasso da transcendência em função de uma imanência pura, absoluta, "dor arenosa do deserto". (NASSAR, 2005, p. 192). Nassar consegue apresentar um romance em que nos deparamos com o esvaziamento da representação e, juntamente com ela, das imagens do pensamento. Na literatura de Nassar, vão se perdendo antigas representações e lentamente seu fio de continuidade e de memória. É o acontecimento marcando as convergências e as divergências de todos os elementos de uma relação. Em André, Ana e o Pai, a vida silenciosamente lapidava as condições que os tornariam tão próximos pela ação da desrazão. Se para Ana, a morte a aguardava pelo caminho da paixão, no Pai, a morte o espreitava pela via da loucura. Não há mais um olhar atento e vigilante da alma, do mundo interior. Em suas dessemelhanças, todos se assemelham. Tornam-se um; possuídos pela mesma força; componentes de um mesmo plano. Intensidade indivisível de uma mesma peça teatral que os impulsiona para a mesma direção: a afecção, a paixão, o excesso, a sensibilidade. 


\begin{abstract}
We will discuss the signs of affection in the novel Lavoura arcaica and their implications in the production of a des-nature and paradoxes. The passages will spring from the liturgical-moral discourse to a heterogeneity that refuses the attachment to old traditions. In the novel, reason, passion and faith are represented throughout the dialogues, serving as justification of the discourses, whether expressed by the father or by the son. Raduan Nassar presents us elements of guilt, law, punishment, tragic, death and joy, all under the form of a discontinuous and visceral narrative flow, in which human relations are established not only by duty but also by a physical and psychic violence, in which the body "cries out" louder than rationality. The problem crossing our text will be: what can literary creation as a work of art (aesthetic creation) teach us about human relations? Would not writing be linked to a "cracking" of the self instead of restoring it? What does it mean to think or say the world through literary creation as aesthetic or the art of writing? Then, Raduan Nassar's literature builds aesthetic, be by the writing style, be by a being of sensations it creates.
\end{abstract}

Keywords: Transgression. Affection. Literary creation. Identity

Referências

DELEUZE, Gilles. Diálogos. Tradução de Eloísa Araújo Ribeiro. São Paulo: Escuta, 1998.

DELEUZE, Gilles. Síntese assimétrica do sensível. In. DELEUZE, Gilles. Diferença e repetição. Tradução de Luiz Orlandi e Roberto Machado. Rio de Janeiro: Graal, 1988, p. 355-414.

JÚNIOR, Bento Prado. Plano de imanência e vida. In.: JÚNIOR, Bento Prado. Erro, ilusão e loucura. Ensaios. São Paulo: 34, 2004, 139-170.

MOISÉS-PERRONE, Leyla. Da cólera ao silêncio. In. Cadernos de literatura brasileira.Raduan Nassar. Rio de Janeiro: Instituto Moreira Salles, 2001, p. 61-77.

NASSAR, Raduan. Lavoura arcaica. São Paulo: Companhia das Letras, 2005. 
